\title{
XVIII. Observations on the development and growth of the epidermis
}

\section{Erasmus Wilson F.R.S.}

To cite this article: Erasmus Wilson F.R.S. (1846) XVIII. Observations on the development and growth of the epidermis , Philosophical Magazine Series 3, 28:185, 82-90, DOI: $10.1080 / 14786444608645366$

To link to this article: http://dx.doi.org/10.1080/14786444608645366

曲 Published online: 30 Apr 2009.

Submit your article to this journal $\sqsubset \pi$

Џ Article views: 2

Q View related articles $\asymp$ 
XVIII. Observations on the Development and Growth of the Epidermis. By Erasmus Wilson, F.R.S., Lecturer on Anatomy and Physiology in the Middlesex Hospital*.

$\mathrm{T} T$ is the commonly received doctrine at the present day, that the cells of the epidermis and of epithelium in general, originate out of materials furnished by the liquor sanguinis or plasma of the blood. In order that this purpose may be effected, the liquor sanguinis is conveyed by endosmosis through the walls of the capillary vessels and through the peripheral boundary of the surface, the "basement membrane" of Bowman. Having reached the exterior plane of the latter, the changes commence which result in the development of granules in the previously fluid liquor sanguinis, or rather, perhaps, in the aggregation of the molecules of the organisable material or blastema, which was previously held in intimate suspension or solution by the liquor sanguinis. Out of the body an action of this kind would be termed coagulation, and where inorganic matter is concerned, crystallization. The process to which I am now referring, though taking place within the body, is analogous to these phænomena, with the difference of being controlled and directed by the power of life, of being, in point of fact, a vital coagulation or crystallization. Indeed, coagulation, although occurring out of the body, and sometimes after the lapse of a considerable period, may be regarded as the last act of vital existence, or as a vestige of the atmosphere of life with which the coagulating fluid was previously charged in abundance.

As regards the tissue under consideration, there is every ground for belief, that the organisable material or blastema of the liquor sanguinis is appropriated by the epidermis the very instant it reaches the exterior plane of the "basement membrane;" some portion of it, and the greater part of the serum of the liquor sanguinis, being taken up by the newly-formed cells to be transmitted in succession to more superficial ranges of cells, and the remaining portion being converted on the spot into the primitive granules of the tissue. This belief is supported by the fact of the absence of any fluid stratum between the epidermis and the dermis, and by the close connexion known to subsist between those two membranes. It is well known that to separate the epidermis from the dermis, until the former is so thoroughly saturated with fluid by maceration as to have acquired a considerable addition to its dimensions in all directions, or until decomposition has com-

* Read before the Royal Society, June 19, 1845, and communicated by the Author. 
menced, is next to impossible; and in the living state of the body, separation never takes place until the mutual connexion between the layers has been destroyed by the effusion of fluid. The microscope gives additional weight to this evidence. I have observed that the cells of the deep surface of the epidermis are in immediate contact with the boundary limit of the dermis, and that moreover it is frequently difficult to determine the exact line between them. I have also made the following experiment:-I cut very thin vertical slices of the skin, at daily periods, from the moment of death until decomposition had become established, and submitted them to the action of the compressor on the field of the microscope, but in every instance, while fresh, the two tissues yielded to the pressure in equal proportion without any separation occurring. As soon, however, as decomposition had commenced, separation was produced, and in the early stages took place with difficulty. This experiment proves that the firm adhesion sub. sisting between the epidermis and dermis is not alone due to the numerous inflexions of the former into the latter, which take place at the sudoriferous tubes, hair tubes, and sebaceous ducts, although these inflexions must co-operate powerfully in the result.

Being desirous of examining the under surface of the epidermis with the higher powers of the microscope, and failing in all my attempts to effect this object by taking the entire thickness of the epidermis or scraping, I awaited the first indication of its separation from the dermis, and then removing it carefully made a thin slice parallel with the surface which I wished to examine. This plan succeeded beyond my expectations; for not only did I obtain parts so diaphanous as to enable me to see the surface distinctly, but the septa between the depressions for the papillæ of the dermis afforded natural laminæ of such transparency as permitted their structure to be well examined.

When the under surface of the epidermis was exposed to view, I found it to be composed of four kinds of elements, arranged in such a manner as to constitute an irregular mosaic plane. These elements are,-1, granules, measuring about $\overline{2} \delta_{0} \frac{1}{0}{ }_{0}$ th of an inch in diameter; 2 , aggregated granules, measuring about $\frac{1}{\pi 0} \delta \sigma^{\text {th }} ; 3$, nucleated granules, measuring $\frac{1}{60} \sigma_{0}$ th to $\frac{1}{400} 0^{\text {th }} ; 4$, cells, measuring $\frac{1}{3000}$ th to $\frac{1}{25} \frac{1}{50}$ th of an inch.

1. The granules, which I may distinguish by the name of primitive granules, are globular in form, homogeneous, solid, brightly illumined by transmitted light when the centre is under the focus of the microscope, but dark when viewed upon the surface, the darkness being increased whenever they are 
congregated in clusters. These granules I conceive to be the first organic shape of the blastema of the liquor sanguinis.

2. The aggregated granules, measuring about $\frac{1}{1} \frac{1}{0} \overline{0} \overline{0}^{\text {th }}$ of an inch in diameter, are minute masses, composed of four, five or. six of the preceding, or as many as can be aggregated without leaving an unoccupied space in the centre of the mass. With an imperfect focus, these granules have the appearance of possessing a transparent globular nucleus, but this appearance ceases when the focus is perfect, and then the component granules are quite obvious, and the centre becomes a dark point, namely, the shadow caused by the meeting of the primitive granules.

3. The mucleated granules, measuring between $\frac{1}{600}$ th and $\frac{1}{400}$ th of an inch in diameter, are in point of construction an "aggregated granule" with a single tier of "aggregated granules" arranged around it, so as to give the entire mass a circular or oval form. The central aggregated granule has now become a nucleus, and at the same time has undergone other changes which indicate its longer existence. For example, the primitive granules composing it are denser than they were originally, and they are separated from each other by a very distinct interstitial space filled with a transparent and homogeneous matter. Sometimes this interstitial substance presses the granules asunder equally on all sides, constituting a circular nucleus; but more frequently two opposite granules are more widely separated than the rest, and the nucleus receives an elongated form. The interstitial substance is most conspicuous at the line of junction of the nucleus with the secondary tier of " aggregated granules," and in this situation gives a defined character to the nucleus. Close observation and a perfect focus render it quite obvious that the peripheral tier of granules are in reality aggregated, they are lighter than the shaded granules of the nucleus, and apparently softer in texture.

The nucleated granules are more or less flattened in form, and present a flat surface of contact with the dermis. It is the latter circumstance that gives the facility of determining their mode of construction.

4. The cells of the deep stratum of the epidermis, measuring $\frac{1}{3000}$ th to $\frac{1}{25} \overline{0} 0$ th of an inch in their long diameter, are the most striking feature of this layer, and may be said to be its chief constituent. They originate, as is evident from their structure, in the nucleated granules previously described, and consist of a transparent layer added to the exterior of the former; or, if I might be permitted to describe them as they appear in their tesselated position, they are constituted by the 
addition of a transparent border to the last-described nucleated granule. The periphery of this transparent border is bounded by a dark interstitial substance, which gives the border a defined ontline; and in the latter situation I imagine a cell-membrane to exist. I am not satisfied, however, that this is the case; and the difficulty of isolating these cells, and their roughness of outline when separated, serve to prove that if a membrane be really present, it must be exceedingly thin and ensily torn. Assuming therefore, from analogy rather than from demonstrative evidence, that there exists a boundary membrane to the bodies I am now describing, I have termed them "cells;" the cavity of the cell I apprehend to be the "transparent border," the "nucleated granule" is the nucleus of the cell, the "aggregated granule" of the latter the mucleolus, and the entire body a "nucleolo-nucleated cell."

Before quitting the structure of the "nucleolo-nucleated cell," or primitive cell of the epidermis, there is a point of much interest to be mentioned with regard to it, which is, that the "transparent border" just described is itself a tier of "aggregated granules." The nucleolus therefore is an "aggregated granule," the nucleus a tier (taking its flat surface) of "aggregated granules" surrounding the former, and the cell a tier of "aggregated granules" enclosing the whole.

To return to the mosaic-like plane of the under surface of the epidermis, the largest of the pieces composing this plane are the nucleolo-nucleated cells. These are placed without order, some being closely pressed together, others being separated by moderate intervals, and here and there some separated by interspaces equal to the breadth of the cells. The interspaces, or intercellular spaces, are occupied by the "nucleated granules," "aggregated granules," and "primitive granules," irregularly set in a homogeneous interstitial substance, which fills up all vacuities. The granules and interstitial substance modify the light transmitted through them variously at different foci of the microscope; sometimes the granules look dark while the interstitial substance is light, and sometimes the reverse is the case.

Such is the structure of the mosaic-like plane of the under surface of the epidermis, and so far, my observations, having reference to facts, are demonstrable and admit of being spoken to positively. The interpretation of the facts I would willingly leave to others, but feel that $I$ am called upon to state any opinion, founded on the above observations, that 1 may have formed of the signification of these appearances. In the first place, then, I must acknowledge myself wholly divided between 
a belief in the formation of the "aggregated granule" by the aggregation of primitive granules, the idea which prompted me to give them that name, and the formation of the aggregated granule by the cleavage of a primitive granule. If this question related merely to the formation of the "primary aggregated granule," it would be unimportant, but it has a more extended application. The outermost layer of the nucleus is composed, as I have shown, of "aggregated granules," and so also is that layer which alone forms the space in the nucleolo-nucleated cells. To them the hypothesis of cleavage of a simple granule would be most suitable, and this theory would explain better than any other, changes which remain to be described in the further growth of the epidermic cell. In the second place, the relation of cell and nucleus is a question on which I feel considerable doubt. The process of development appears to consist in the successive production of granules, one layer of granules succeeding another, so that if the organisable principle exist in each separate granule, the organisable force may be supposed to be more and more weakened in successive formations, until the moment arrives when it ceases entirely. Is that which I have described as a nucleolo-nucleated cell really a cell or still a nucleus? The only solution of the question that occurs to me is, determining the presence of a cell-membrane, in which I have not satisfactorily succeeded.

Admitting the nucleolo-nucleated bodies now described to be cells in their earliest state of formation, their size is $\frac{1}{300}$ th to $\frac{1}{2} \frac{1}{50}{ }^{\text {th }}$ of an inch in the long diameter, and that of their nucleus from $\frac{1}{6000}$ th to ${ }_{45^{1}}^{1} 0^{\text {th }}$ of an inch. In the stratum immediately above the deepest layer, I find cells measuring $\frac{1}{200}$ th of an inch with nuclei of $\frac{1}{450} \overline{0}$ th. Above these, cells measuring $\frac{1}{1800}$ th, with nuclei varying from $\frac{1}{4000}$ th to $\frac{1}{5000}$ th, and above the latter cells measuring $\frac{1}{150} \mathrm{t}$ th, with nuclei of $25^{2} 0^{\text {th. }}$ In following the layers of the epidermis upwards to the surface, cells may be observed possessing every intermediate degree of size between the last-mentioned cell, namely $\frac{1}{1500} 0^{\text {th }}$ and $\frac{1}{6} \sigma^{\text {th }}$, which is the measurement of the scales which constitute the uppermost stratum of the epidermis. It must not be supposed, however, that the growth of the epidermic cells reaches its maximum only at the surface: I have found cells of that magnitude in the deeper strata; and there is every indication of the growth of these cells being completed in the stratum immediately above the mosaic-like layer.

Young cells are remarkable for the large size of the nucleus as compared with the entire bulk of the cell; and it is quite 
evident also that the nuclei, up to a certain point, grow with the cells, their mode of growth appearing to be, the separation of the original granules by the deposition between them of interstitial matter; and in addition, as I believe, hy cleavage of the latter and the consequent multiplication of the granules. In cells measuring $\frac{1}{2} \frac{1}{0} 0$ th and $\frac{1}{130} 0$ th of an inch, I found the granular character of the nucleus to be very manifest. Besides growth, it is apparent that other changes are taking place in the nucleus ; imbibition and assimilation of organisable material must necessarily be in action in order to accomplish the formation of interstitial matter; but in addition to this the central granules undergo another change, by which they are altered in character and become distinguished from the rest when submitted to chemical experiment. For example, when dilute acetic acid is added to the cells measuring $\frac{1}{200} \overline{0}$ th of an inch and less, the entire nucleus is rendered transparent and less discernible than before; but when cells of a somewhat larger size, and consequently longer growth, are submitted to the same process, the nucleus is rendered much more distinct than it was previously. But the body which is made so conspicuous in this latter experiment is not the entire nucleus, but simply the central and older granules of the nucleus; the younger granules retuin the character of those of the young cells, they are made more transparent than they were before, and have faded from sight. I may mention also, that the nucleus brought into view by the acetic acid is more or less irregular in form, and has the appearance of being constituted by the fusion of the original granules. How much of this appearance may be real and how much the effect of the acid, I do not pretend to say, and I set no value on the experiment beyond the demonstration of the mere fact which it is made to illustrate.

I now turn to the growth of the cells. I have remarked, in an earlier paragraph, that the formation of the young cell appears to be due to the development of a stratum of "aggregated granules" externally to the nucleated mass, which I have regarded as the cell-nucleus. Now nothing is more certain than that the growth of the cell is due to a successive repetition of this process, the growth of the cell-membrane being consentaneous with the development and growth of "aggregated granules" within it. In cells of $\frac{1}{180} \frac{\text { th to }}{15 \frac{1}{5}} \mathrm{t}^{\text {th }}$ of an inch, the "aggregated granules" of the periphery are not easily discernible; but in cells measuring $\frac{1}{100} 0^{\text {th }}$, and thence upwards to the complete size of the epidermic cell, the fact is quite evident, and is apparent even in the cell-scale. Indeed a cell, at the full period of growth, is a kind of cell-microcosm, 
containing in its interior secondary cells, tertiary cells, nucleolo-nucleated cells, nucleated granules, aggregated granules and primitive granules.

It will be observed that this hypothesis of cell-growth differs from that of Schwann. The theory of Schwann always appeared to me to be incompetent to the explanation of the growth of the large scale of epidermis and epithelium in a tissue manifestly subjected to considerable pressure. I sought in vain for the watch-glass cells, elliptical cells, and globular cells in the epidermis; but my search has been rewarded by the discovery of the above-described beautiful process of formation and growth. It will be seen that, according to this view of the growth of the epidermic cells, they never possess anything approaching to a globular shape, that the scales are not flattened spheres, but on the contrary always possessed a flattened form, and have increased by a peripheral growth. This mode of growth again is made manifest by the observation of a vertical section of the epidermis. The most careful examination can distinguish no difference between the size of the deeper and the superficial strata of cells; they have all the same average thickness, all the same average length, - an appearance easily explained when we regard them as parentcells containing secondary and tertiary cells of the same average size as the cells of earlier formation. It is true that the complete size of a cell is very quickly attained, and that its growth, taking place in the deepest stratum of the epidermis, could not be expected to produce any difference of character in the middle and superficial strata; but this is not mentioned, as far as I know, by Schwann.

The process of growth here described explains also the fact of the disappearance of the nucleus in the scales of epidermis. The outermost granules of the nucleus have become the nuclei or nucleoli of secondary cells, and have consequently been moved away from their original position in the performance of their office of centres of growth to secondary cells. The original nucleus, therefore, is not lost, but merely robbed of some of its component granules, which may be discovered in many parts of the epidermic scale, instead of being concentrated in a single mass. In these scales, and particularly in epithelial scales, the central and dense part of the original nucleus is generally perceptible; in the latter it constitutes the scale nucleus; and in the epidermic scale there is always some one little mass larger than the rest, particularly if the scale have been for some time immersed in fluid, as when it is examined in the serum of a blister. In an epidermic cell, measuring $\frac{1}{60}$ th of an inch in long diameter, I found several 
secondary cells measuring $\frac{1}{15} \overline{0}$ th, others measuring $\frac{1}{500} \sigma^{\text {th }}$; and in the interstices, primitive granules, aggregated granules, and nucleated cells.

My observations, it will be seen, have been chiefly directed to the epidermis, and I am prevented at present from carrying then further, but $I$ bave no doubt that the epithelium will be found to be identical in the phænomena of development and growth with the epidermis. I have observed the same structure in the epithelium of the mouth and fances, and also in that of the bladder and vagina. Incomplete epithelial cells, measuring $\frac{1}{5} 50$ th and $7 \frac{1}{60}$ th of an inch from the fauces, presented a very remarkable appearance; they had a rounded lobulated border, evidently composed of a row of secondary cells and a depressed centre, as though the action were subsiding in the latter, while it was progressing in the circumference.

Another illustration of the structure now described, I found in the cells of melanosis, and in the pigmentary cells of the choroid membrane of the eyeball. I am induced to believe that the same structure will be discovered more extensively than at present can be anticipated. The corpuscles of melanosis, according to my observations, are parent-cells, having an average admeasurement of $\frac{1}{100} \sigma^{\text {th }}$ of an inch, containing secondary cells and nucleated and aggregated granules, as well as separate primitive granules. The "aggregated granules" measured from $\frac{1}{110} 00$ th to $\frac{1}{7000}$ th of an inch, and the primitive granules about $\overline{2} \frac{1}{0} 0 \overline{0} 0$ th.

There is another feature in the history of development of the epidermic cell, which I regard as peculiarly interesting. This relates to an organic change taking place in the assimilative powers of the primitive granules, by which the latter are altered in their colour, in short, are converted into "pigment granules." Pigment granules appear to differ in no respect from the "primitive granules," excepting in that of colour, and perhaps also in chemical composinion. They have the same globular form, the same size, and occupy the same position in the cell, being always accumulated around the nucleus, and dispersed less numerously through the rest of the cell. 'The nucleus of the cell in the epidermis of the Negro appears to consist wholly of pigment irranules, while in the European there is a greater or less admixture of colonred and uncoloured granules. The central granules are generally lighter in tint than the rest, and give the idea of a colourless nucleolus, while those around the circumference are deeper coloured. Besides a difference in the depth of colour of the separate granules entering into the composition of a single Phil. Mag. S. 3. Vol. 28. No. 185. Feb. 1846. 
cell, there is also much difference in the aggregate of the granules composing particular cells. For example, intermingled with cells of a dark hue, there are others less deeply tinted, which give the tissue in which they are found a mottled appearance. This fact is well-illustrated in the hair, and also in the nails, in which latter it is no uncommon thing to find an isolated streak produced by the accumulation of a number of cells containing coloured granules, in the midst of colourless celis.

When pigment granules are examined separately, they offer very little indication of the depth of colour which is produced by their accumulation. I have observed some to have the hue of amber, while other's scarcely exceeded the most delicate fawn. The depth of colour of the deep stratum of the epidermis in the Negro, is evidently due to the composition of that layer of these granules, while the grayness of the superficial layers of the same tissue results not merely from the desiccation of these granules, but also from the fact of those subsequently produced being less strongly coloured, and also from the addition of a colourless cell-membrane.

'The epidermic scale of the Negro has a mottled appearance, from the numerous secondary nuclei and their attendant coloured granules which are scattered through its texture.

P.S. Since my communication of the above paper to the Royal Society, I have confirmed its truth by further observations, and have ascertained that the same principle of growth is applicable to the formation of mucus and pus-corpuscles.

December 1845.

XIX. On the Aberration of Light, in Reply to Mr. Stokes. $B y$ the Rev. J. Chaldis, M.A., Plumian Professor of Astronomy in the University of Cambridge*.

THE remarks Mr. Stokes has made on my Explanation of the Aberration of Light, since they have little reference to the more important parts of the communication, require from me but brief notice.

I agree with all Mr. Stokes has said about the direction of vision through a telescope, but cannot perceive what it has to do with aberration. In selecting the wire of an astronomical telescope for the terrestrial object to which the direction of the celestial object is referred, I had not the least reference to vision through a telescope. It would have answered my pur-

* Communicated by the Author. 